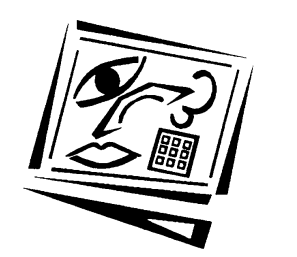

\title{
Object of the activity systems as a major barrier to the creative use of ICT in schools
}

\author{
Lim Cher Ping \\ Nanyang Technological University, Singapore
}

\begin{abstract}
Despite the research and investment of Information and Communication Technologies (ICT) in schools, many teachers still use it as a neutral tool; that is, a tool that can be used to carry out the same teaching and learning activities as have been undertaken previously with non-ICT tools. This paper adopts activity theory as a conceptual framework to describe and analyse how the objectives of two economics courses are shaped by their participants and learning environments, and in turn, how these shared objectives affect the way ICT is used in these courses. The paper goes on to suggest that the object of the activity systems poses a major barrier to the creative use of ICT in schools.
\end{abstract}

\section{Introduction}

Many large scale studies have documented positive learning outcomes from using Information and Communication Technologies (ICT) in schools (Sivin-Kachala 1998; Wenglinsky 1998; Mann, Shakeshaft, Becker \& Kottkamp 1999; Holmes, Savage \& Tangney 2000). These studies claim that ICT develops a culture of thinking; one that "engages students with challenging yet personally meaningful problems, draws on students' conceptual and cultural world of experiences, and promotes active and independent learning among students" (Fisher, Dwyer \& Yocam 1996, p.10). Despite the credibility of these studies and the huge capital investment of ICT in schools by government bodies in the United Kingdom (UK), the use of ICT by teachers has been generally low both in frequency and variety (McKinsey \& Company 1997; Williamset al 1998; Mulkeen 2000).

To develop a culture of thinking among students, teachers must use ICT creatively. That is, teachers must move away from being the exclusive source of expertise and authority, towards exploring the opportunities and limitations of ICT, organising activities to take up its opportunities and address its limitations, reflecting upon the activities and re-adapting them 
accordingly (Lim 2000). Various reasons have been cited for the underutilisation of ICT: lack of staff development, lack of availability and access to ICT resources, lack of support from ICT developers and school administrators, as well as classroom management issues and problems. These pertinent issues are stumbling blocks for many teachers who lack the supportive environment necessary for the creative use of ICT to develop a culture of thinking in their courses. Although many imaginative and practical proposals have emerged to address these problems, the fundamental question of "What are the objectives of the academic course?" is left unattended.

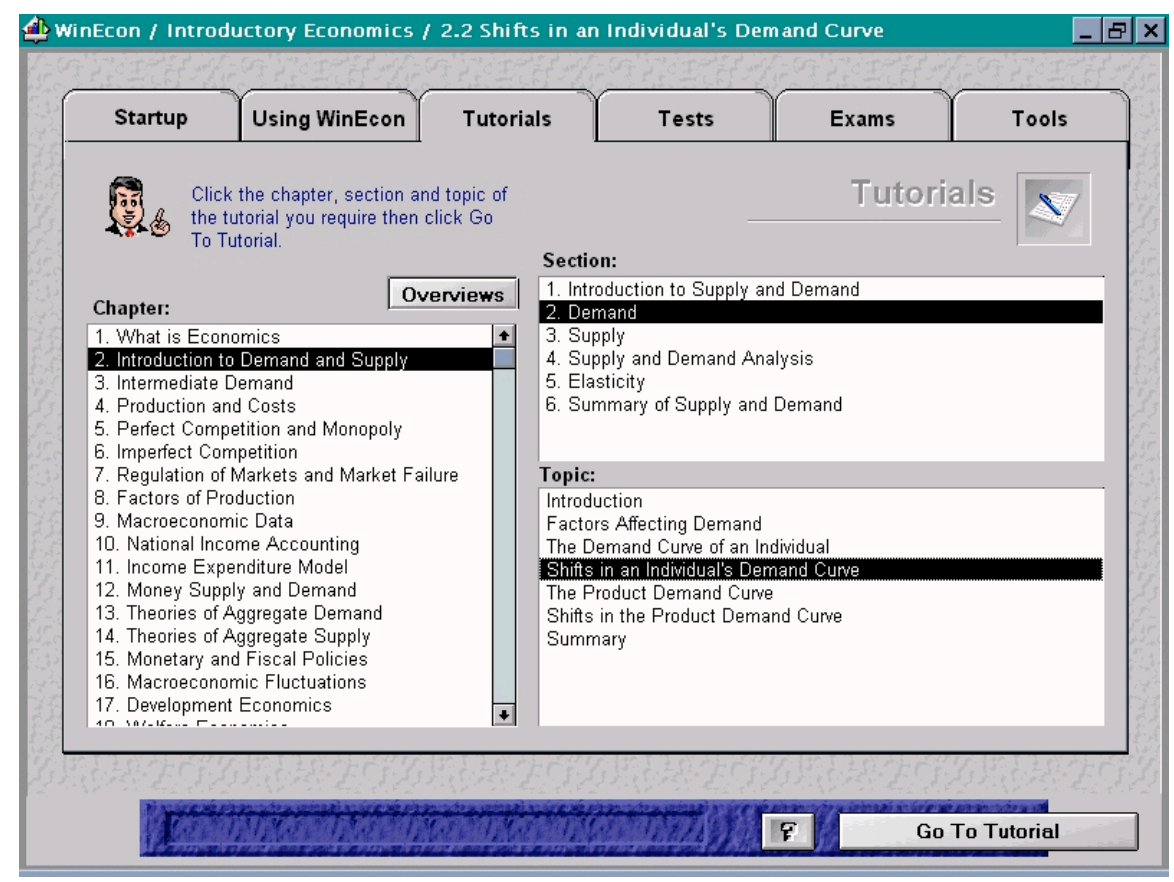

Figure 1: The WinEcon Package

Based on a collective case study of the use of WinEcon in two economics departments in the UK, this paper suggests that teachers are more likely to use ICT creatively if the objectives of their courses are consistent with the culture of thinking. The paper describes and analyses how the objectives of the A-level Economics courses are shaped by their participants and learning environments, and in turn, how these shared objectives affect the ways WinEcon is used in these courses. WinEcon is a windows based ICT package for teaching and learning introductory economics. The core learning material covers the whole syllabus of the A-level Economics 
course. The ICT package offers more than one hundred hours of tutorial material and includes self assessment questions, an economic database, an economic glossary and references to leading economic texts (see Figure 1).

\section{The A-Level Economics course and WinEcon}

The A-level Economics course offered in British schools is a rigorous one, covering a wide range of topics under microeconomics and macroeconomics. This two-year course consists of lectures, tutorials and field visits. Although there are several A-level examination boards that economics departments can choose from, the main aim of the courses is to think 'in an economics way'. It implies an understanding of "why economics exists", and an appreciation of "the purpose, procedures and rules of economics discourse - the economics perspective and methodology - so that they are able to participate in it even if their contribution is an unsophisticated one" (Thomas, 1985, p.57).

To facilitate students to think 'in an economics way', the A-level Economics course must promote learner autonomy, and provide an access into the unnatural world of economic concepts and ideas. Without autonomy and access, students are likely to be plagued by the problem of inert knowledge, and approach the discipline as bundles of facts and descriptions. And as a result, they may lack an appreciation of and ability to participate in the economics way of thinking. It is not the intention of this paper to dismiss traditional classrooms for failing to support the economics way of thinking, but rather the paper takes the stance that WinEcon offers teachers more options to create a learning environment that enables students to think 'in an economics way'.

The cognitive opportunities of WinEcon in introductory economics courses have been studied and discussed in various literature (Sloman 1995; Soper 1997; Brooksbank, Clark, Hamilton, \& Pickernell 1998; Lim 1998, 2000, 2001). WinEcon develops learner autonomy and allows access to the world of economic concepts and ideas, and hence, mediates between the individual student and the object of thinking 'in an economics way'. However, it cannot be assumed that "as long as a support system is available, people will more or less automatically take advantage of the opportunities that it affords" (Perkins 1985, p.12). The cognitive opportunities of WinEcon must be considered together with the learning environment in which it is situated. That is, the study of WinEcon must consider the dynamics, inter-relatedness and interdependency of linkages between participants, ICT and non-ICT tools, and cognition in these environments. The conceptual framework of activity theory was adopted to provide a well developed and consistent methodology for the study of the learning environment that WinEcon was situated. 


\section{Overview of activity theory}

Over the last decade, activity theory has been adopted and developed as a framework for researching ICT in education settings (Holland \& Reeves 1994; Verenikina \& Gould 1997; Engeström 1999). Activity theory draws on the Vygotskian cultural-historical theory of learning, with activity as probably the most important concept. Activity is driven by a collective object (goal) and motive, but it is realised in goal oriented individual and group actions. The centrality of activity to cognition is reflected in Leont'ev's (1981, p.46-47) assertion:

Human psychology is concerned with the activity of concrete individuals, which takes place whether in a collective - that is, jointly with other people

- or in a situation in which the subject deals directly with the surrounding world of objects - e.g. at the potter's wheel or the writer's desk ... if we removed human activity from the system of social relationships and social life, it would not exist ... the human individual's activity is a system in the system of social relations. It does not exist without these relations.

Therefore, activities are systems in the system of social relations. A human individual never acts directly on or reacts directly to the environment. Cultural means, tools and signs mediate the relationship between human participants and the objects of the environment. In this sense, the study of ICT in schools is no longer restricted to the interaction between the computer and the participants, but rather how ICT is embodied within a socially constituted learning environment (Crook 1991).

\section{Activity system as unit of analysis}

Cultural-historical activity theory takes a collective object oriented activity system as its prime unit of analysis (Cole \& Engeström 1993; Engeström, Miettinen, \& Punamäki 1998). The unit of analysis allows one to observe the actual processes by which cognition and cognitive development shapes and is shaped by its context, where the context is the activity system. It integrates the subject (individual participant), the object, the tools and the dynamic nature of human activities. Cole and Engeström (1993) represent the idea of activity systems with an expanded version of the classical mediational triangle (see Figure 2).

The classical mediational triangle draws on Vygotsky's (1978) higher and elementary functioning: 'unmediated' (elementary) functioning occurs along the base of the triangle, and 'mediated' (higher) functioning is the interaction between the subject and object (task) mediated by tools at the vertex of the triangle. However, this basic mediational triangle fails to account for the collective and dynamic nature of activities. The expanded version situates the subject in a community comprising of multiple 
individuals and groups who share the same general object. There is division of labour in the community where the distribution of tasks, powers, and responsibilities are continuously negotiated among its participants. And there are rules that mediate the relations between the subject and its community to "specify and regulate the expected correct procedures and acceptable interactions among the participants" (Cole \& Engeström 1993, p.7).

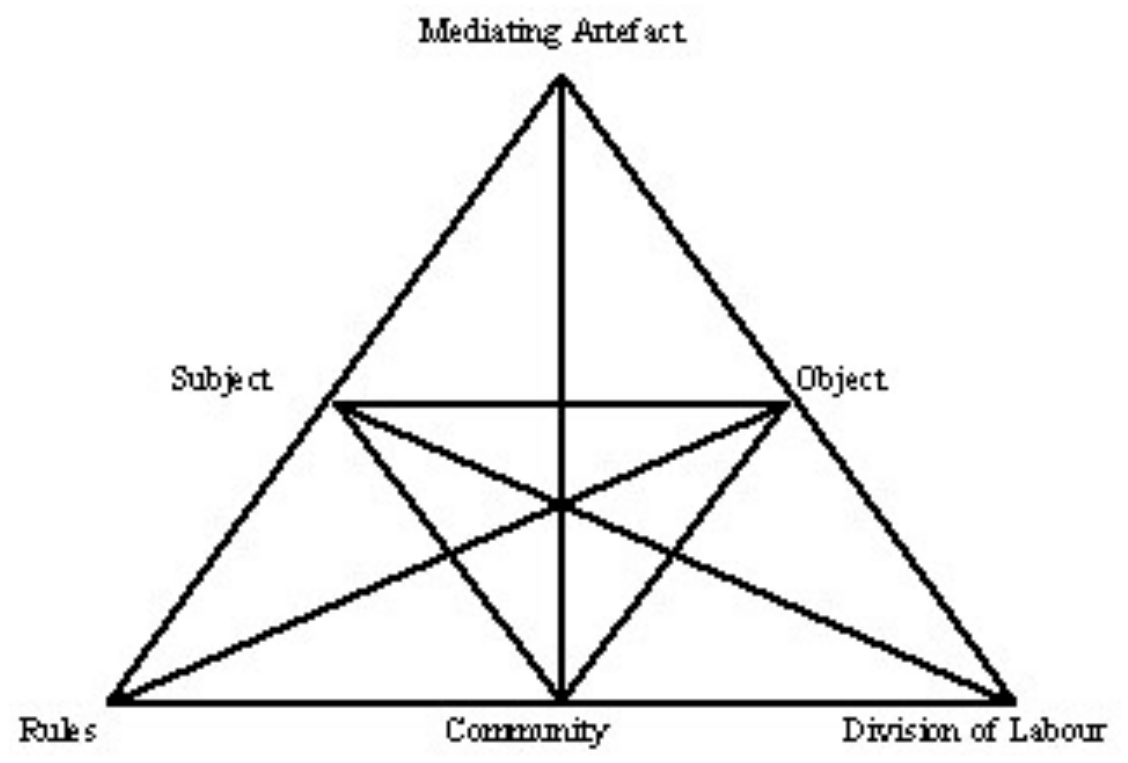

Figure 2: The mediational structure of an activity system (adapted from Cole and Engeström (1993), p.8, Figure 1.3)

\section{Object of the activity systems as the focus of attention}

Activity theory is based on the notion of object oriented activities. Leont'ev (1978) points out that the concept of object is already contained in the very concept of activity as there is no such thing as objectless activity. An object is both something given and something projected or anticipated. The subject constructs the object, and singles out those properties that prove to be essential for developing social practices in particular contexts. Therefore, the object manifests itself in different forms for different participants and at different moments of the activity (Engrestrom \& Escalante 1996). 
To achieve the object of the activity systems, tools are employed to mediate between the subject and the object. The tool through which the subject interacts with the world depends on his/her object, and this shapes the interpretation, relevance and meaning of the mediational tools. That is, the subject perceives and takes up the opportunities of the tools, according to their relevance to the object; establishing a possible relationship between the object of the activity system and how the tools are used.

For example, the introduction of ICT into schools is supposed to mediate between students and higher order thinking. However, schools are results oriented organisations; the rat race among schools is given a boost by the published league tables (based on academic performance) in the nation's mass media to help parents and students make informed choices. Schools put pressure on teachers and students to improve the results in national examinations, so that their ranking will be maintained or improved. And hence, the object of 'improving examination results' may negate the opportunities of ICT to develop higher order thinking skills among students.

\section{The study of WinEcon in the economics course}

In this study, the activity systems were the ICT and non-ICT lessons in the economics courses during the period of the study. Taking an activity system of a WinEcon lesson, the specific elements in the learning environment fitted into the various components in the mediational triangle. The subject was the individual student and the object was assumed to be the course objective of thinking 'in an economics way'.

A pool of ICT and non-ICT tools (including WinEcon) in the computer room mediated the interactions between the subject and object. These tools consisted of WinEcon, other ICT packages, whiteboard, whiteboard markers, notebook, pens, data projector, projector screen, overhead projector, and textbooks. The subject belonged to a community in which "each participant made significant contributions to the emergent understandings of all members, despite having unequal knowledge concerning the topic under study" (Palincsar, Brown, \& Campione 1993, p.43).

The community consisted of his/her classmates and teachers situated in the socio-cultural setting of the computer room mediated by rules and division of labour. The rules included general rules like computer lab rules and regulations, and more specific ones like the procedures to navigate WinEcon. The role that each participant of the community played fall under the division of labour. 


\section{'Creative' and 'uncreative' use of WinEcon}

In order to facilitate the student to think 'in an economics way', the activity system must be considered as a whole to promote learner autonomy, and provide an access into the world of economic concepts and ideas (Lim 2001). However, the object in economics courses may not always be thinking 'in an economics way', and there may be constraints imposed by the socio-cultural context in which WinEcon is situated. Participants then interpret and attach meaning to WinEcon according to its relevance to their object under conventionalised constraints. These interpretations and meanings affect the 'creative' or 'uncreative' use of WinEcon as a mediational tool in the activity systems. In this paper, the use of WinEcon is considered with respect to the object of the activity systems, which is the focus of attention.

If the object is for the students to perform well in their examinations, WinEcon is most likely to be used as an information dispensing or concept reinforcing tool to mediate direct instruction. Students absorb the knowledge that is dispensed by WinEcon, and this knowledge is wrung out during examinations. WinEcon is then used as a purveyor of knowledge and students treated as recipients of knowledge. Such uses of WinEcon are 'uncreative' as it mediates the kind of teaching and learning activities traditionally mediated by a teacher at a blackboard, or a textbook prior to a lecture. The tools mediating the activities might have changed over the years, but the methods employed remain constant (Stone 1999).

The 'creative' use of WinEcon requires a shift away from the transmission model of teaching and a shift towards largely untested alternative methods of teaching and learning that are mediated by WinEcon. This is only possible if the object of the activity systems is thinking 'in an economics way'. Such uses of WinEcon facilitate the acquisition of important cognitive skills required for effective economic analysis by allowing students to be constructors of ideas and defenders of those constructions (Jonassen 1996). While the teacher's role in these activities has changed to a coach, model and facilitator, WinEcon is now a cognitive tool for engaging and enhancing students' thinking 'in an economics way'.

Based on the above discussions, two research questions are generated:

- How is the object of the activity systems shaped by the participants and learning environment of the economics course?

- How does the object of the activity systems affect the creative use of WinEcon in the economics course? 


\section{The collective case study}

The conceptual framework of activity theory provided the parameters, the tools and general guide of how to proceed with the research. To provide an intensive and in depth examination of how the objectives of the A-level Economics courses were shaped by its participants and learning environments, and in turn, how these shared objectives affected the way WinEcon was used in the courses, there was a need to draw on multiple sources of information in the socio-cultural setting. Case study research is the most appropriate tradition of inquiry as it "permits a researcher to reveal the way a multiplicity of factors have interacted to produce the unique character of the entity that is the subject of study" (Thomas 1998).

The collective case study was the situation of WinEcon in two economics departments in the UK, offering A-level Economics, with site licenses to WinEcon. The economics departments in Berkeley and Oxform School (names of schools were changed to ensure anonymity) were selected after the screening phase as they met the following characteristics:

- WinEcon had been used for at least one academic year;

- WinEcon was in the department's scheme of work;

- WinEcon was used at least twice a month in each economics class;

- WinEcon was supported by and is supporting other ICT and non-ICT activities in the course.

The fieldwork in Oxform School was carried out during the Autumn term of $1998 / 99$, between 5 to 23 October. The school was situated in the suburbs of a commercial city in the English midlands. There were two teachers in the economics department: $\mathrm{Mr}$ Trueman, the head of department, and $\mathrm{Mr}$ Barnes (names have been changed to ensure anonymity). Both of them taught the lower-sixth and upper-sixth classes. The class size of the former was seventeen, and the latter nine. The mode of assessment adopted by Oxform School was an end of year examination without project work. Besides WinEcon, the department used a variety of ICT packages such as Running the British Economy (a simulation package) and SECOS (a data base package).

The visit to Berkeley School took place during the Spring term 1998/99, from 11 to 29 January. The school was in a declining town, twenty kilometres from an industrial city in the north of England. The economics department in Berkeley School had eighteen lower-sixth students, and five upper-sixth ones. The two teachers Mr Deeks, the head of department, and Mr Mitchell taught both classes. The department adopted the modular mode of assessment where the students had to sit for five examinations in two years. WinEcon and BizEd (a website for business and economics learning resources) were the only ICT packages used in the department. 
Participant observations, face to face interviews with teachers, and focus group interviews with students were used in the multiple strategies process to gather accounts of different realities that had been constructed by various groups and individuals in the learning environment. By comparing one account with accounts from another standpoint or method, it was possible to test and sometimes revise or extend that account on the basis of more sufficient data; and hence, enhancing the reliability and validity of the study.

\section{Participant observation}

On all occasions in the study, the researcher stayed somewhere between the extremes of being a complete observer and complete participant. He observed and interacted with the students and teachers, neither participating in the decision making processes nor fully committing to the department's values and goals. Participant observation facilitated the collection of rich detailed data in natural settings, provided a better 'insider perspective' (Alder \& Alder 1996), and put the researcher in a better position to generate and refine questions during the interviews with students and teachers regarding an observed behaviour or action.

Taking activity systems as the unit of analysis, both ICT and non-ICT lessons were observed during the three weeks period in each department. In Oxform School, all ten ICT lessons observed were WinEcon ones, conducted in the computer room. The twelve non-ICT lessons observed included classroom lectures, tutorial discussions, debates, and follow up activities of WinEcon lessons. In Berkeley School, six out of the eight ICT lessons observed were WinEcon ones. The other two lessons were mediated by BizEd. Fourteen non-ICT lessons were observed and they included classroom lectures, and tutorial discussions.

\section{Face to face interviews with teachers}

Although participant observation allowed for the collection of data through the researcher's direct contact with the learning environment, it was not always possible to have intimate, repeated and prolonged involvement in the life and community of the participants. Much of what the researcher could not observe had to be acquired through interviews. Moreover, the interviews helped to explain certain behaviours or actions of the participants that had been observed.

Two one-hour interviews were planned and conducted with each teacher, one during the first week and the other during the third week of the case study. All interviews were tape recorded. A list of topics that the researcher wanted the teacher to talk about was generated for the interview: course objectives and challenges, use of WinEcon, supporting 
ICT and non-ICT tools and activities, and roles of teachers and students in the learning environment. The list served as an interview guide that enabled the researcher to formulate questions to fit naturally into the interviews.

\section{Focus group interviews with students}

Three groups of four to six students were chosen from each department for the one-hour focus group interviews. The focus group interviews relied on the interaction between participating students to elicit their point of view by allowing a struggle of understanding of how others interpreted key issues and a debate of problems raised (Morgan 1993). It elicited in depth, albeit subjective information on students' perceptions towards WinEcon, and the activity systems that WinEcon was situated in.

A list of topics were generated to guide the interviews: expectations of and problems in the course, experience of using WinEcon, supporting ICT and non-ICT tools and activities, and roles of students and teachers in the activity systems. Although there were many similar questions for each focus group, certain questions were only specific to a particular group or department. For example, only students in Oxform School were asked to compare the differences between the WinEcon lessons conducted by the two teachers. The question was case specific, generated after observing WinEcon lessons conducted by both teachers in Oxform School.

The design and methods discussed in this section allowed for a holistic approach towards the study of the unit of analysis in its natural setting. Although the study might be an exploratory one, the conceptual framework of activity theory informed its design and methods. The next section first describes how the participants and learning environment shapes the object of the activity systems. It then discusses how the cognitive opportunities of WinEcon are perceived and taken up by the participants, given the object; and hence, highlighting how the object of the activity systems poses as a major barrier to the creative use of ICT in schools.

\section{Sample findings}

\section{Object of the activity systems}

The two departments adopted different examination boards for the A-level Economics course. The main objective specified by the boards was to think 'in an economics way'. Although all four teachers agreed that activities should be designed to meet that objective, three felt that achieving good results was the primary objective of the course. The three teachers perceived the objectives of thinking 'in an economics way' and achieving good results as contradictory. Mr Deeks of Berkeley School argued that 
"it's not a major fault of the school in emphasising grades as we have to keep our position in the league table". Only Mr Trueman of Oxform School viewed the objectives as complementary since the examination was "still about using economic theories to analyse problems that may be completely unfamiliar to students", and that would "differentiate the good students from the not so good ones".

The introduction of league tables had certainly put pressure on teachers to maintain or improve their schools' academic standing. As the A-level remained the most popular route into higher education (DfEE 1999), there was also pressure from parents to ensure that their children were admitted into universities of their choice. The better links between parents and schools might create even greater pressure on teachers to produce results, as parents took on a greater role in influencing school policies and practices. Inevitably, achieving good results threatened to take precedence over thinking 'in an economics way' as the primary objective of the course.

With results as the bottom line, the teachers of Berkeley School and Mr. Barnes of Oxform School, admitted that they were under pressure to ensure that their students thought "in an examination mode" (Formal interview with Mr. Mitchell of Berkeley School). Activities were then organised to equip students with examination skills and knowledge to perform well in their A-level Economics examinations. The teachers adopted much tested and didactic approaches to teaching and learning, and discussed previous years' examination questions. However, teachers were quick to point out that these activities should not be carried out at the expense of students' perception and treatment of the discipline.

Students' expectations of the course also have an effect on the object of the activity systems. In Berkeley School, the students' main expectation was to get good grades in Economics to accumulate enough points for gaining admission to higher education. Most of their responses during the focus group interviews were "to get an A" or "to get good grades to be admitted to a course of my choice". The modular mode of assessment might have brought about the examination culture in the department. Students started preparing for one examination almost immediately after they had completed the previous one. Their socio-economic background might also have affected their examination orientation. To many of them, getting into universities might be seen as the only way out of their present socioeconomic conditions.

Given the expectations of the students and the priorities of the teachers in Berkeley School, the object of thinking 'in an economics way' appeared to be overshadowed by the common object of thinking in an examination mode'. The object of most activities was to ensure good examination results. Mr. Mitchell admitted that about two-thirds of the course was 
dedicated to preparing students for the modular examinations. As a result, students were further enculturated into thinking in an examination mode', as they participated in the activity systems.

Students' expectations of the course in Oxform School were different from those in Berkeley School. Students from the former department expected economics concepts and ideas to relate to real world situations. They were always asking question such as "If perfect competition does not hold in the real world, why are we learning it?" or "How can we hold all other things constant in theory and expect everything to change in real life?" Coupled with Mr Trueman's view that the two objectives were complementary, many activities organised in Oxform School supported the economics way of thinking.

Although Mr Barnes did not agree whole heartedly with these activities, he was aware that some of the activities he organised have to meet the students' expectations of relating economic concepts and ideas to the real world. If he organised all activities to get students to think "in an examination mode", students might lose interest in the subject as they were unable to appropriate the way of thinking that failed to meet their needs. Via the process of mutual negotiation and appropriation, some activities were carried out to meet the needs of students, but at the same time, ensure that students were prepared for the examinations. However, as the head of department, $\mathrm{Mr}$ Trueman had greater bargaining power in shaping the scheme of work for the economics course.

In the two departments, the quest for good results played as important a part in shaping the object of the activity systems as the object of thinking 'in an economics way'. The evidence supports Bruner's (1996, p.31) claim that "education is up to its elbows in the struggle for distinctions". Such a claim is also echoed by other academics such as, Bourdieu (1991) and Postman (1995). Berkeley School appeared to be a "market" where its participants "trade" the ways of thinking 'in an economics way' for "distinctions". Although there was some "trade" going on in Oxform School, its socio-cultural setting and participants kept the object as the economics way of thinking. Since both departments employed WinEcon as a tool to mediate between the subject and the object, the differences in the object of the activity systems would affect the use of WinEcon.

\section{Object of the activity systems and creative use of WinEcon}

Since the objects of the activity systems were different in each department, and between the two departments, the interpretation, relevance and meaning of WinEcon as a mediational tool differed among the activity systems; and hence, the use of WinEcon also differed. In Berkeley School, 
where good A-level results was the object of most of its activity systems, WinEcon was perceived by students and teachers as a self paced reinforcement tool for concepts and theories that have been taught in traditional classroom activities, and a revision tool for examinations. After one of the WinEcon lessons, some students wanted to print out the WinEcon screen to take away as notes for revision purposes.

To ensure that students were task oriented during WinEcon lessons, $\mathrm{Mr}$ Deeks provided them with checklists and advance organisers. Although the task orientation allowed students to gain better access to the content knowledge presented in WinEcon, the object of the activity systems did not support access to higher cognitive levels of the discipline. Since the teacher perceived WinEcon as a tutor that reinforced and revised concepts, there was a lack of activities organised to support discussions and interactions among the participants, or to encourage self interrogating when students were working through WinEcon. These processes would have developed students' problem solving skills and epistemic knowledge.

In Oxform School, WinEcon was perceived and used by Mr Trueman more as a cognitive tool to allow students to make their own notes from a variety of tools. These tools included the basic textbook, reference books, and newspaper articles. Although he sometimes used WinEcon to reinforce or revise certain concepts that had been taught in class, he preferred to use WinEcon prior to in depth teaching of the concepts. He believed that for students to think 'in an economics way', they must be empowered to construct their own knowledge from materials presented in WinEcon and other tools.

An overview of the concepts and objectives of the task were always given before the students started working on WinEcon. With the worksheet as a guide, the students first reviewed materials from textbooks, reference books, as well as WinEcon, and then considered their relevance to the concepts under study. The note taking encouraged them to articulate and critically reflect upon their own understanding of the concepts. It also allowed the teacher to engage in one to one discussions with students, and promoted more discussions among students.

After the WinEcon lesson, discussions were carried out away from WinEcon, during the next non-ICT lesson or a few lessons later. In these discussions, students articulated and extended their understanding, and questioned the articulation provided by others. These discussions also allowed Mr Trueman to identify the misconceptions, extend and question their articulation of the concepts, summarise the discussion by linking the various concepts, and provide real world case studies for further discussion and debate. 
Mr. Barnes, on the other hand, perceived WinEcon in the same light as participants in Berkeley School. The majority of his WinEcon lessons were for reinforcement or revision purposes. However, he allowed opportunities for one to one discussions with his students, and made note taking a requirement for most of his lessons. He was made aware of the discussions supported by WinEcon, and the importance of note taking when Mr Trueman invited him to team teach two of the WinEcon lessons in academic year 1997/98. Mr Barnes tried to use WinEcon prior to teaching a concept once (he made sure that it was not a key concept), but found that "a risky business" as it was not examination oriented. He also complained that students were often confused and lost when asked to make their own notes for a new topic. It should be noted that he did not prepare any worksheet to guide students in their note taking, or conduct discussion of the notes taken during the WinEcon lessons.

\section{Relationship between the object of the activity systems and the creative use of WinEcon}

Figure 3 is a schematic representation of the positive relationship between the object of the activity systems and the creative use of WinEcon as a mediational tool. At one end is Berkeley School where the object was thinking 'in an examination mode', and WinEcon was used as a mediational tool to support that way of thinking. The teachers had perceived WinEcon as a means to enhance the grades of their students, and had used it as a reinforcement and revision tool. Such uses of WinEcon were uncreative as the teachers were still carrying out the activities in the same way as traditional teaching and learning.

At the other end, is Mr Trueman of Oxform School where WinEcon was used to support students to think 'in an economics way', the object of the activity systems. He organised higher level cognitive tasks of note taking that were not possible in the non-ICT lessons. With such creative uses of WinEcon in the activity systems, students were no longer treated as vessels to be filled or as receivers at the end of the transmission line; but rather, they were more likely to claim ownership of the economics concepts and ideas through such activities. Mr Barnes of Oxform School lies somewhere in between the two of them. He was aware of certain opportunities of WinEcon through team teaching with Mr Trueman, but failed to take up some of these opportunities, as they did not match with his object.

The situation of WinEcon in Berkeley and Oxform School suggested a positive relationship between the object of the activity systems and the creative use of WinEcon. However, it might not apply to all cases. The failure to use ICT creatively might be due to a lack of awareness of the match between the object and the cognitive opportunities of ICT, a lack of 
knowledge to take up the opportunities, or other constraints imposed by the socio-cultural setting of WinEcon. For example, teachers might be constrained by time to design activities to take up the opportunities of ICT.

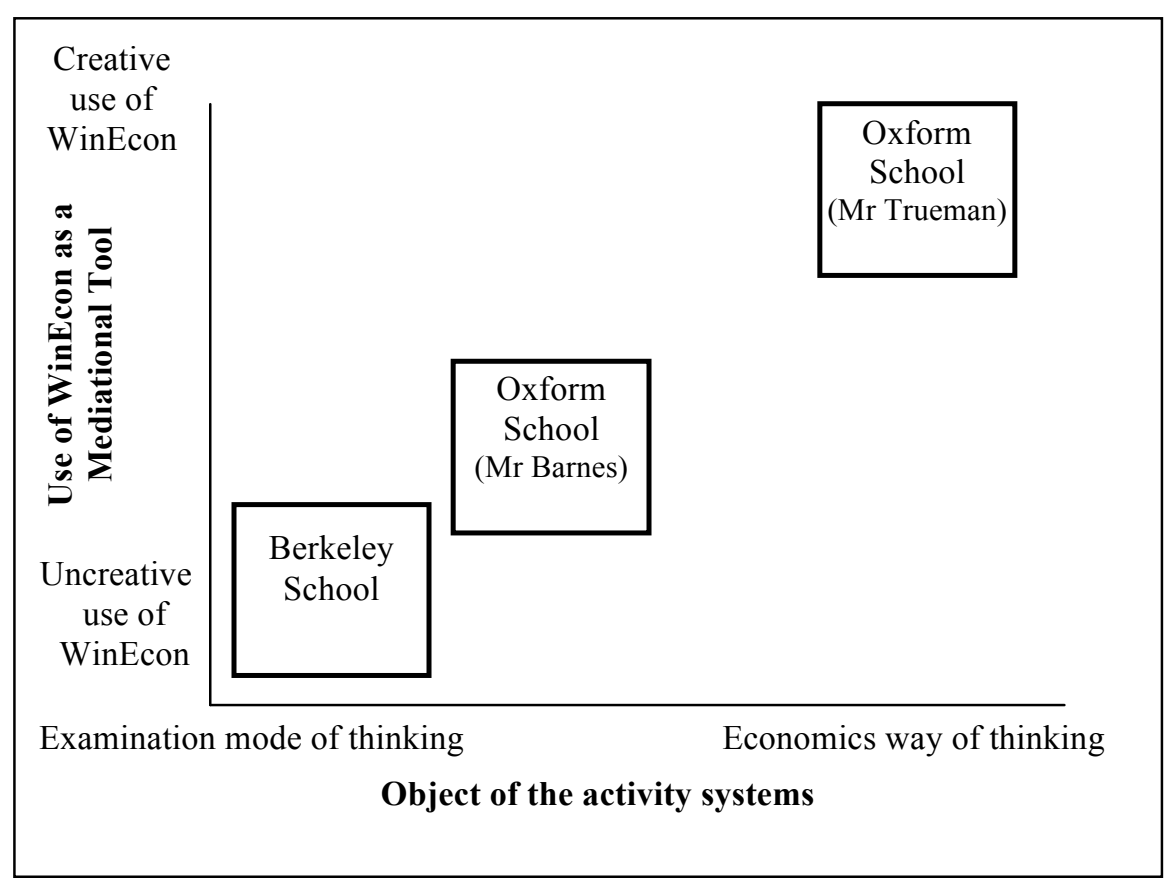

Figure 3: A schematic representation of the relationship of WinEcon as a mediational tool to the object of the activity systems in which it is situated.

These findings and arguments supported Vygotsky's (1978) definition of tools as being used to mediate goal directed activities under conventionalised constraints. Although the relationship between the use of the mediational tool and the object of the activity systems had been discussed, an account of the constraints imposed by the socio-cultural setting was not within the scope of this paper.

\section{Conclusion}

From the discussion in this paper, it was clear that the object of the activity systems was significant in shaping the creative use of WinEcon in the economics course. The object might not always be the main aim of the Alevel Economics course as stated by examination boards and economics 
educators. But rather, the object was more likely to be influenced by the learning environment and its participants. The socio-cultural elements at each level of context interacted and gave meaning to one another. Moreover, different objects might co-exist within the same activity systems to meet the different expectations of participants, and the pressure from higher levels of socio-cultural context.

As long as the bottom line hinges on examination results, many of the cognitive opportunities of ICT in education will not be perceived. Even if teachers are made aware of these opportunities through professional development workshops, perceived opportunities that do not fit into the object are unlikely to be taken up; and hence, the object of the activity systems becomes a major barrier to the creative use of ICT.

\section{Change in the object of the activity systems}

The introduction of ICT into schools requires teachers to interact creatively with it by planning and organising activities to develop a culture of thinking among students. However, the over emphasis on results in schools may put pressure on teachers to conduct more remedial and drill and practice classes, as well as discuss more exam type questions. They may follow the transmission model of teaching when using ICT to meet the object of achieving good examination grades.

As we move into the twenty-first century, students must be developed as lifelong learners. They need to learn how to seek out new information, think critically and show initiative to meet up with the challenges of the fast changing world. The creative use of ICT in schools will support this development process. However, the object of thinking 'in an examination mode' may negate the opportunities of ICT by opting for activities that churn out straight 'A's students over activities that develop students who are creative, versatile, and open in their perspectives. There is indeed an urgent need for a shift of the object of the activity systems from one that honours examination grades to one that promotes lifelong learning.

\section{References}

Alder, P. \& Alder, P. (1994). Observational techniques. In N. Denzin \& Y. Lincoln (Eds), Handbook of Qualitative Research. London: SAGE Publications.

Bourdieu, P. (1991). Language and Symbolic Power. Cambridge (MA): Harvard University Press.

Brooksbank, D.J., Clark, A., Hamilton, R. \& Pickernell, D.G. (1998). Views from the trenches: Lessons from the introduction of WinEcon into a first year undergraduate programme. Computers in Higher Education Economics Review, 12(1), 13-18. 
Bruner, J.S. (1996). The Culture of Education. Cambridge (MA): Harvard University Press.

Cole, M. \& Engeström, Y. (1993). A cultural-historical approach to distributed cognition. In G. Salomon (Ed), Distributed Cognitions: Psychological and Educational Considerations. New York: Cambridge University Press.

Crook, C. (1991). Computers in the zone of proximal development: Implications for evaluation. Computers and Education, 17(1), 81-91.

Denzin, N. (1970). The Research Act in Sociology. London: Butterworth.

Department for Education and Employment (1999). Green Paper on Teachers: Meeting the Challenge of Change. London: Department for Education \& Employment (DfEE).

Engeström, Y. (1999). Expansive visibilisation of work: An activity-theoretical perspective. Computer-Supported Cooperative Work, 8, 63-93.

Engeström, Y. \& Escalante, V. (1996). Mundane tool or object of affection? The rise and fall of Postal Buddy. In B. Nardi (Ed.), Activity Theory and Human-Computer Interaction. Cambridge: Cambridge University Press.

Engeström, Y., Miettinen, R. \& Punamäki, R-L. (Eds) (1998). Perspectives on Activity Theory. Cambridge: Cambridge University Press.

Fisher, C., Dwyer, D.C. \& Yocam, K. (1996). The Apple classroom of tomorrow An overview. Education and Technology - Reflections on Computing in Classrooms. San Francisco: Jossey-Bass Publishers.

Holland, D. \& Reeves, J.R. (1994). Activity theory and the view from somewhere: Team perspectives on the intellectual work of programming. Mind, Culture and Activity, 1, 9-24.

Holmes, B., Savage, T. \& Tangney, B. (2000). Innovation in Learning in the Information Society: A Comparative International Study. Dublin, Trinity College.

Jonassen, D.H. (1996). Computers in the Classroom: Mindtools for Critical Thinking. Englewood Cliffs (NJ): Prentice Hall.

Leont'ev, A.N. (1981). The problem of activity in Psychology. In J.V. Wertsch (Ed), The Concept of Activity in Soviet Psychology. New York: Sharpe.

Lim, C.P. (1998). The effect of Computer-Based Learning (CBL) support package on the learning outcome of low-performance economics students. Computers in Higher Education Economics Review, 12(1), 19-26.

Lim, C.P. (2000). Situating ICT in the Economics Course. Unpublished PhD Dissertation. England: University of Bristol.

Lim, C.P. (2001). Learner control and task-orientation in a hypermedia learning environment: A case study of two economics departments. International Journal of Instructional Media, 29(3), 1-15.

Mann, D., Shakeshaft, C., Becker, J. \& Kottkamp, R. (1999). West Virginia's Basic Skills/Computer Education Program: An Analysis of Student Achievement. Santa Monica, CA: Milken Family Foundation. 
McKinsey \& Company (1997). The Future of Information Technology in UK Schools. London: McKinsey \& Company.

Morgan, D.L. (1993). Successful Focus Groups: Advancing the State of the Art. Newbury Park: SAGE.

Mulkeen, A. (2000). Laptops in the classroom. Access Magazine. 18 June 2000.

Palincsar, A.M., Brown, A.L. \& Campione, J.C. (1993). First-grade dialogues for knowledge acquisition and use. In E.A. Forman, N. Minick \& C.A. Stone (Eds), Context for Learning: Socio-cultural Dynamics in Children's Development. New York: Oxford University Press.

Perkins, D.N. (1985). The fingertip effect: How information-processing technology changes thinking. Educational Researcher, 14 (7), 11-17.

Postman, N. (1995). The End of Education: Redefining the Value of School. New York: Alfred A. Knopf.

Sivin-Kachala, J. (1998). Report on the Effectiveness of Technology in Schools, 1990-1997. New York: Software Publisher's Association.

Sloman, J. (1995). WinEcon. Economic Journal, 15(432), 1327-1346.

Soper, J. (1997). Integrating interactive media in courses: The WinEcon software with workbook approach. Journal of Interactive Media in Education, 97(2). [viewed 8 July 1998] http:/ / www-jime.open.ac.uk/97/2/

Stone, L.L. (1999). Multimedia instruction methods. Journal of Economic Education, 30 (3), 265-275.

Thomas, L. (1985). The core of Economics - A psychological viewpoint. In G.B.J. Atkinson (Ed), Teaching Economics (Third Edition). London: Heinemann Educational Books.

Thomas, R.M. (1998). Conducting Educational Research: A Comparative View. Westport, Bergin \& Garvey.

Verenikina, I. \& Gould, E. (1997). Activity theory as a framework for interface design. ASCILITE'97, Perth, 611-615. http: / / www.ascilite.org.au/conferences / perth97/ papers / Verenikina/Verenikina.html

Vygotsky, L.S. (1978). Mind in Society: The Development of Higher Psychological Processes. Cambridge (MA): Harvard University Press.

Wenglinsky, H. (1998). Does it Compute? The Relationship between Educational Technology and Student Achievement in Mathematics. Washington: Educational Testing Service Policy Information Center.

Williams, D., Wilson, K., Richardson, A. Tuson, J. \& Coles, L. (1998). The Way Forward-Recommendations. Aberdeen: Robert Gordon University.

Dr Lim Cher Ping is an Assistant Professor in the Instructional Science Academic Group at the National Institute of Education, Nanyang Technological University, 1 Nanyang Walk, Singapore 637616 Tel: +65 7903279 (Office) +65 3994057 (Fax) Email: cplim@nie.edu.sg 